Revista de

Contabilidade e

Organizações

www.rco.usp.br
DOI: http://dx.doi.org/10.11606/rco.v9i23.83452
Journal of

Accounting and

Organizations

www.rco.usp.br

\title{
Análise de estilo de fundos imobiliários no Brasil
}

Daniel Scolese ${ }^{\mathrm{a} ;}$ Daniel Reed Bergmann ${ }^{\mathrm{b} ;}$ Fabiana Lopes da Silva ${ }^{\mathrm{c} ;}$ José Roberto Ferreira Savoia $^{\mathrm{d}}$

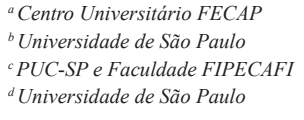

\section{Informações do Artigo}

\section{Histórico do Artigo}

Recebido: 31 de julho de 2014

Aceito: 08 de junho de 2015

Palavras chave:

Fundos Imobiliários

Mercado de Renda Fixa

Ações e Análise de Estilo

\begin{abstract}
Este trabalho tem por objetivo investigar o retorno dos fundos de investimentos imobiliários, buscando identificar seu estilo e, consequentemente, seu comportamento frente aos índices do mercado financeiro brasileiro do segmento de renda fixa, de renda variável e do segmento imobiliário para o período de 2011 a 2015. O estudo concluiu que mesmo que o fundo imobiliário esteja naturalmente lastreado a um ativo real, considerado com um ativo seguro e com baixa volatilidade, verificou-se que, pela dinâmica inerente às variações de preços e riscos associados aos FIIs, há um caráter híbrido desses fundos no que tange ao mercado de renda fixa e variável. Os resultados apontaram que os retornos dos FIIs acompanham de forma mais pronunciada os juros prefixados e os retornos do mercado imobiliário, corroborando com os resultados empíricos internacionais de Niskanen e Falkenbach (2010) e Ghosh, Miles e Sirmans (1996).
\end{abstract}

Copyright (C) 2015 FEA-RP/USP. Todos os direitos reservados

\section{INTRODUÇÃO}

Nos últimos anos, observou-se um notório crescimento do interesse por investimentos no segmento imobiliário, com destaque para os Fundos de Investimentos Imobiliários, também conhecidos como Fundos Imobiliários ou simplesmente por sua abreviação FIIs.

Segundo a Instrução CVM 472, de 31 de outubro de 2008, que dispõe sobre as normas gerais que regulamentam os Fundos de Investimentos Imobiliários, este pode ser definido como a comunhão de recursos captados por meio do sistema de distribuição de valores mobiliários e destinados à aplicação em empreendimentos imobiliários.

Sobre os principais fatores que propiciam a expansão dos FIIs, destacam-se (i) aspectos ligados a estabilidade econômica observada desde a década e 90, com as medidas implementadas para o controle da inflação (Plano Real), (ii) avanços nas leis que regulam o setor imobiliário e (iii) os aumentos dos investimentos externos, reflexo das crises econômicas em países desenvolvidos (FERREIRA, 2011).

Os investimentos imobiliários possuem aspectos de consumo e de investimentos. Imóveis podem ser vistos como moradia e também como uma parcela importante do investimento das famílias. A inseparabilidade das decisões de consumo e investimento em imóveis tornam-se uma restrição à otimização das decisões de um investidor neste mercado. No entanto, a existência de fundos imobiliários pode proporcionar uma solução para os investidores otimizarem suas decisões de consumo e investimento, proporcionando melhor acesso a este mercado, como no caso de pequenos investidores que podem investir nesse segmento em frações de imóveis.

Valim (2013) complementa que no caso brasileiro o investimento imobiliário tornou-se mais atrativo em decorrência da queda da inflação e foi incentivado por mudanças nas taxas de juros e nos incentivos governamentais

Autor Correspondente: Tel (11) 1125063470

E-mail: daniel.scolese@gmail.com (D. Scolese); danielrb@usp.br (D. R. Bergmann); fabianalopes@usp.br (F. L. Silva); jrsavoia@usp.br (J.R.F.Savoia)

Centro Universitário FECAP - Avenida Liberdade, 532 - CEP 01502-001 - São Paulo-SP, Brasil. 
ao setor.

De acordo com Kucko (2007) as vantagens que os fundos de investimentos imobiliários oferecem em termos de diversificação, liquidação, custos e retornos reais contribuem para explicar o seu sucesso como instrumento de poupança.

Com o ambiente econômico e social favorável, o setor imobiliário se aqueceu e, consequentemente, o mercado de capitais aproveitou-se desse momento, incentivando o mercado a lançar mais produtos financeiros mais simplistas e com menor burocracia, o que contribui para aumentar a popularidade frente aos investidores desse tipo de investimento (FRANKE, 2012).

O investidor em FIIs objetiva a diversificação de seu portfólio e a obtenção de um fluxo de renda constante através do recebimento de aluguéis. A percepção das pessoas físicas é de que o investimento é seguro e apresenta baixa volatilidade em comparação com ativos de renda variável, como a bolsa de valores. No entanto, há um componente de risco atrelado à variação do preço do imóvel, e um componente de renda fixa (aluguéis), funcionando, portanto, como um instrumento híbrido entre renda fixa e renda variável.

A escolha dos ativos que irão compor o fundo (seletividade) é fundamental para o desempenho do fundo, uma vez que o mercado imobiliário não é homogêneo e apresenta diferentes padrões de comportamento entre os tipos de imóveis selecionados. Além disso, quando negociado em Bolsa de Valores, a cota do fundo sofre influência dos fatores de mercado que atuam sobre todos os ativos de renda variável. Nesse contexto, emerge a seguinte questão de pesquisa: Quais são os fatores determinantes do retorno dos FIIs no mercado Brasileiro no período de 2011 a 2015? Assim, o objetivo deste estudo é investigar o retorno dos fundos de investimentos imobiliários, buscando identificar seu estilo e, consequentemente, seu comportamento frente aos índices do mercado financeiro brasileiro do segmento de renda fixa, de renda variável e do segmento imobiliário.

Sharpe (1992) fez a proposição de um modelo que identifica qual é a fonte de risco a que uma carteira de investimento está exposta, o qual ficou conhecido como Return Based Style ou análise de estilo baseada no retorno. Ela pode ser definida como uma comparação entre retornos dos fundos e os retornos de índices representativos do mercado, visando identificar as efetivas classes de ativos que determinam seu estilo (ALMEIDA, MENDES e NAZARETH, 2007).

O mapeamento das variáveis determinantes no retorno dos fundos imobiliários se torna útil não só para investidores individuais, mas também para gestores de portfólio, o que possibilita uma melhor compreensão do comportamento do Fundo Imobiliário, não só de forma isolada, mas também como um ativo integrante de um portfólio diversificado com outras classes de ativos.

Para tanto, no referido artigo serão analisadas a influência das seguintes variáveis sobre o retono dos FIIs: (i) as variações dos retornos dos índices IMA-B5, IMA-B5+, IRF-M da Anbima, (ii) as variações dos retornos do IBOVESPA e índice de Dividendos (IDIV) e (iii) as variações do índice IGMC-I da Fundação Getúlio Vargas, que representa o impacto do setor imobiliário comercial.

Este trabalho trata de um tema de finanças que pode servir para a contabilização dos fundos imobiliários em bancos por evidenciar o estilo destes fundos, quer seja renda variável ou renda fixa. Este artigo é organizado em cinco seções, além desta introdução. A segunda seção apresenta o referencial teórico sobre fundos de investimento imobiliário e análise de estilo. A terceira seção discute os aspectos metodológicos, enquanto que na quarta seção é apresentado os resultados. Por fim, na seção 5, são expostas as considerações finais e conclusões da pesquisa.

\section{REFERENCIAL TEÓRICO}

\subsection{Os Fundos Imobiliários no Brasil}

A participação do investimento de forma indireta no segmento imobiliário vem crescendo, seja entre investidores individuais, seja entre investidores institucionais como fundos de pensão, seguradoras e gestores de investimentos.

Investimentos diretos em imóveis exigem elevado desembolso de capital, pois normalmente o valor mínimo de cada investimento corresponde ao valor de cada imóvel adquirido. Já o Fundo de Investimento Imobiliário possibilita o acesso ao pequeno investidor que, com um valor relativamente baixo, pode investir no setor imobiliário e, em muitos casos, possibilita a diversificação com a participação simultânea em diversos 
imóveis.

A possibilidade de ampliação do acesso a investidores no segmento imobiliário foi um dos principais fatores que estimulou o surgimento no mercado do conceito de fundo de investimento imobiliário, regulamentado pela legislação brasileira a partir da década de 90, por meio da lei 8668/93 e da Instrução 205/94 da Comissão de Valores Mobiliários (CVM, 2010).

O FII é um condomínio de investidores com o objetivo de aplicar recursos financeiros, em empreendimentos imobiliários, a serem implantados ou já concluídos. O cotista do FII não tem nenhum direito real sobre os imóveis e empreendimentos integrantes do patrimônio do fundo. Assim, a regulamentação exime o titular das cotas de responder pessoalmente por qualquer obrigação legal ou contratual relativa aos imóveis e empreendimentos integrantes do fundo ou do administrador.

A administração do fundo compreende a gama de ofícios direta ou indiretamente relacionados ao seu funcionamento e manutenção, que pode ser prestada pelo próprio administrador ou por terceiros por ele contratados, desde que devidamente habilitados.

A qualificação e experiência do administrador do FII é um aspecto de grande importância na seleção do investimento uma vez que este é o proprietário fiduciário dos imóveis e direitos integrantes do patrimônio do fundo, exercendo todos os direitos e obrigações em beneficio dos cotistas. De acordo com a CVM (2010) as principais vantagens dos FIIs são: (i) acesso ao mercado imobiliário; (ii) ganhos de escala; (iii) diversificação; (iv) simplificação; e (v) possibilidade de fracionar o investimento.

Um dos aspectos que mais tem atraído a atenção dos pequenos aos grandes investidores na forma indireta de investimento em imóveis é o incentivo fiscal. O FII possui isenção de impostos como PIS, COFINS e Imposto de Renda (Incidirá IR nas aplicações do caixa do fundo). Entretanto, para que o fundo tenha o benefício tributário, é necessário ainda distribuir aos cotistas no mínimo $95 \%$ de seu lucro pelo menos a cada seis meses. Também não é permitido ao fundo investir mais de $25 \%$ de seu patrimônio em empreendimento imobiliário com pessoa a ele ligado.

Para as pessoas físicas que investem em FIIs, a Lei $n^{\circ}$ 11.033/04 confere a isenção de imposto de renda para os rendimentos distribuídos pelo fundo, desde que se trate de fundo com no mínimo 50 quotistas e tenham suas cotas negociadas exclusivamente em bolsa ou mercado de balcão organizado. Além disso, o investidor pessoa física não pode ter rendimentos que representem mais do que $10 \%$ dos lucros percebidos pelo FII ou deter mais do que $10 \%$ das cotas do fundo.

Com relação às pessoas jurídicas, tanto os rendimentos como os ganhos de capital, uma vez distribuídos pelos fundos imobiliários (apuração de acordo com o regime de caixa), recairá imposto de renda na fonte, à alíquota de $20 \%$. Vale lembrar que o ganho de capital fruto da alienação das cotas no mercado secundário é tributado à alíquota de $20 \%$.

Considerando que o Fundo Imobiliário é uma alternativa bastante procurada para investimento direto em imóveis, visando o benefício da valorização deste mercado no Brasil, bem como à atratividade da geração de renda, este trabalho tem uma contribuição ao melhor entendimento do segmento e pode respaldar as estratégias de gestores dos fundos.

\subsection{Análise de Estilo}

Um fundo de investimento possui diversas opções de alocação de recursos, cabendo ao gestor atuar de acordo com as suas estratégias e escolhas de ativos. As questões fundamentais são em que classes de ativos e em que proporções os recursos deverão ser alocados (SHARPE, 1988).

Segundo CHAN et al. (2002), o desempenho dos administradores não é homogêneo em relação às suas decisões de investimentos. Contribuem para este fato o conjunto das preferências por técnicas qualitativas ou quantitativas, por exemplo, que os levam a adotar diferentes abordagens de seleção de ativos ao longo do tempo.

Brown e Goetzmann (1997) afirmam que a análise estilo de gestão é empregada para a mensuração de performance e na remuneração de gestores, o que obriga as classificações serem objetivas, baseadas em dados empíricos, consistente entre os diversos grupos de gestores e ser relacionada a estratégia de gestão por eles adotadas. Dessa forma podem ser evitados os riscos morais derivados da apresentação e divulgação de performance dos fundos pelos próprios gestores. Isto é crucial para que os investidores possam realizar suas escolhas e outorgar 
mandatos de administração sobre os recursos de forma isenta.

Um dos principais benefícios de se identificar as classes principais de ativos nas quais um fundo investe é avaliar o potencial de retorno e risco em função do mix de ativos. Além disso, tal análise pode melhorar a comparabilidade entre a performance de fundos, uma vez que possibilita agrupar fundos semelhantes em termos de ativos e riscos.

Segundo Yoshinaga et al. (2007) um dos precursores na realização de estudos quantitativos de análise baseada em modelos lineares de retornos foi Jensen (1968), ao classificar os fundos de investimento conforme as suas características de risco sistêmico. Posteriormente, Sharpe $(1988,1992)$ desenvolveu a Análise de Estilo Baseada em Retorno para avaliar o grau de exposição das carteiras de um fundo de investimento a determinadas classes de ativos. A técnica também é conhecida como Modelos de Fatores para Classes de Ativos (Asset Class Factor Models). A partir dos retornos históricos do fundo e dos ativos pré-determinados, é aplicada uma regressão múltipla para estimar a alocação do gestor nessas diferentes classes de ativos ao longo do tempo. Desta forma, é possível inferir o "estilo" adotado por este gestor, o que se configura de grande utilidade para controlar os riscos de sua atuação.

O modelo utilizado por Sharpe se tornou uma ferramenta amplamente utilizada ao longo das décadas posteriores, seja isoladamente, ou em conjunto com outras técnicas multivariadas ou de séries de tempo, tentando identificar a existência de grupamentos, ou mensurando riscos das carteiras. Assim, o modelo segue a seguinte forma geral:

$$
R_{P i}=\left\{b_{1 P} F_{1 i}+b_{2 P} F_{2 i}+\cdots+b_{k P} F_{k i}\right\}+e_{P i}
$$

Tal que representa o retorno da carteira $P$ no instante $\mathrm{i}, \mathrm{F}_{\mathrm{li}}$ a $\mathrm{F}_{\mathrm{ki}}$ representam os fatores de 1 a k no instante $\mathrm{i}$ e os coeficientes a representam as sensibilidades no retorno da carteira $\mathrm{P}$ aos fatores de $1 \mathrm{a} \mathrm{k}$. $\mathrm{O}$ é o resíduo do modelo. Sharpe $(1988,1992)$ relaciona ainda três características necessárias a serem atendidas pelas classes de ativos presentes no modelo:

i. sejam exaustivas, isto é, todas as variáveis independentes relevantes devem ser colocadas no modelo e representarem um segmento do mercado financeiro significativo para a explicação do desempenho do fundo;

ii. sejam mutuamente exclusivas; e

iii.não apresentem multicolinearidade.

Coelho, Minardi e Laurini (2009) ao avaliarem fundos multimercado, afirmam que o modelo de fatores identifica o estilo de gestão do fundo e também se aplica à gestão de risco de mercado. Ressaltam a necessidade de se usar séries não muito longas de dados, em virtude da dinâmica das carteiras, o que afeta a sensibilidade dos retornos aos fatores.

Alexander e Dimitriu (2004) concluíram num estudo de estilo que a seleção de gestores pelo índice "alfa" permite melhorar o retorno de um portfólio de fundos e reduzir a sua variância. Através deste índice é possível identificar a contribuição dos administradores, através da correta escolha dos ativos, o que caracteriza o papel ativo do gestor.

Fung e Hsieh (1997) enfatizam que o modelo de Sharpe é focado apenas no retorno dos ativos que compõe a carteira, e não na dinâmica das estratégias adotadas. Tal limitação não é relevante nos estudos de fundos imobiliários, pois de forma diferente de fundos de ações ou hedge funds (SCHUTT e CALDEIRA, 2013), as carteiras não sofrem alterações frequentes e, também, são vedadas posições vendidas ou alavancadas.

\subsection{Estudos Empíricos Sobre os Determinantes da Rentabilidade dos Fundos de Investimentos Imobiliários}

A fim de justificar a escolha das variáveis utilizadas no presente artigo foram levantados os principais estudos empíricos que abordaram o retorno dos fundos imobiliários e REITS Real Estate Investment Truste e como eles se relacionam com os ativos imobiliários e outros ativos financeiros do mercado de capitais.

O fundo imobiliário apresenta duas fontes primordiais de retorno: a valorização dos imóveis e o fluxo de dividendos. Este último é, de fato, uma perpetuidade com pagamentos periodicamente distribuídos, porém difere do cupom de um título de renda fixa por não ser garantido o seu pagamento.

Com relação às evidências da dependência de valorização das cotas dos Fundos Imobiliários com o setor 
imobiliário, foi apresentado por Cosentino e Alencar (2011), estudo onde constataram que os FIIs apresentaram forte relação de seus retornos com o aumento dos preços dos imóveis. Sobre a mesma temática têm-se também os estudos de Nishigaki (2007). Para capturar a variação do segmento imobiliário, foi usado o índice IGMI-C, Índice de Rentabilidade do Mercado Brasileiro de Imóveis Comerciais calculado e disponibilizado pela FGV. A coleta do IGMI-C é contínua, com dados recebidos mensalmente. Entretanto, a periodicidade de cálculo e a divulgação são trimestrais.

Considerando que o valor das cotas dos Fundos Imobiliários pode ser influenciado por fatores de mercado que atingem todas as empresas e também pelas expectativas embutida nas negociações das cotas no mercado secundário foram utilizados os índices de renda variável Ibovespa e IDIV (índice de Dividendos) para medir a sensibilidade dos FIIs aos movimentos de bolsa. O IDIV é um índice composto pelas empresas listadas na bolsa que se destacaram em termos de remuneração aos investidores, sob a forma de dividendos e juros sobre o capital próprio. O Ibovespa, por ser o índice mais líquido do mercado brasileiro, foi escolhido para representar a tendência do comportamento do investidor em bolsa, sendo uma proxy da variabilidade do retorno do mercado.

Para o modelo americano de Fundo Imobiliário, denominado de REIT (Real Estate Investiment Trust), diversas pesquisas empíricas buscaram identificar a relação entre retorno do fundo com ativos imobiliários com outros ativos financeiros, dentre eles destacam-se: Ghosh, Miles e Sirmans (1996) evidenciaram que o REIT apresentou uma forte correlação positiva com o S\&P500 de 1985 a 1996, evidenciando os benefícios de diversificação para os investidores nesses fundos.

Niskanen e Falkenbach (2010) encontraram que os REITs europeus apresentam uma correlação negativa com o mercado de renda fixa, evidenciando que os investidores preferem investir neste mercado em momentos de alta da taxa de juros da economia.

Clayton e Mackinnon (2001) encontraram evidências de que a relação entre os retornos dos REITs com títulos de renda fixa, ações small-caps, ações large-caps e imóveis (não securitizados) mudam ao longo do tempo e que a intensidade destas ligações de retorno é cíclica. Niskanen e Falkenbach (2010) sugerem a existência de uma significante correlação positiva entre REITs e ações, especialmente small-caps e ações de valor. Eid (2010), ao analisar a introdução de fundos imobiliários em uma carteira de investimentos, pode-se afirmar que, ao serem integrados em uma carteira de investimentos junto com ativos de renda fixa e ações, a carteira apresentou resultado satisfatório, melhorando a relação retorno e risco.

Glascock, Lu e So (2002) afirmam que há uma relação negativa entre os retornos dos REITs com a inflação da economia, resultante dos efeitos de mudanças nas políticas monetárias. A este respeito, Porto e Rocha Lima Jr. (2010) afirmam que a inflação afeta o retorno de empreendimentos imobiliários, uma vez que os contratos de aluguel normalmente são corrigidos periodicamente por índices de inflação. Desta forma, o índice IMA-B5, que representa uma carteira com títulos NTN-B, será adotado como variável explicativa para capturar tanto o efeito da inflação como também a variação da taxa de juro real de títulos com maturidade de até cinco anos. Adicionalmente, será utilizado o índice IMA-B5+ para capturar os efeitos inflacionários e também a variação da taxa de juro real de títulos com maturidade superior a cinco anos. Analogamente, utiliza-se o IRF-M como proxy da expectativa futura das taxas de juros prefixadas praticadas pelo Banco Central. Segundo Vilella e Leal (2008), o comportamento do IRF-M é derivado da expectativa do mercado para as taxas de juros de curto e médio prazos. Por fim, utiliza-se também a variável IGMI-C (Índice Geral do Mercado Imobiliário Comercial) da Fundação Getúlio Vargas para representar a valorização do mercado imobiliário comercial e a rentabilidade auferida pelos aluguéis.

He, Webb e Myer (2003) e Huang e Lee (2009) evidenciaram que os REITS são negativamente relacionados com variações das taxas de juros praticadas no mercado norte-americano. No Brasil, Mugnaini, Silva, Vieira e Maia (2008), ao analisarem o desempenho de sete fundos imobiliários, no período de janeiro de 2003 a agosto de 2005, constataram que a performance dos fundos foi inferior aos índices de mercado e outras classes de ativos, superando por pouco a poupança e a inflação.

\section{METODOLOGIA}

A pesquisa adotada se baseia predominantemente em uma abordagem empírico-analítica com enfoque quantitativo baseado na análise de regressão. A amostra compreende 15 fundos imobiliários listados em bolsa e que apresentaram negociação nos 51 meses do período compreendido entre janeiro de 2011 a março de 2015. A escolha do período é coincidente com a existência de um índice próprio para o setor imobiliário - IGMI-C, 
calculado pela Fundação Getúlio Vargas.

Uma das relevantes contribuições deste estudo é utilizar um índice próprio do setor e que é diretamente atrelado ao desempenho do setor imobiliário. Estudos anteriores procuravam analisar o estilo destes fundos com base em índices macroeconômicos, porém, não capturavam a valorização do setor imobiliário e a remuneração dos aluguéis. Os dados foram obtidos através do sistema Economática em março de 2015. Segue o Quadro com a amostra dos quinze fundos selecionadas para análise.

Quadro 1. Descrição da Amostra dos Fundos Imobiliários.

\begin{tabular}{|c|c|}
\hline \multicolumn{2}{|c|}{ Descrição dos Fundos } \\
\hline FII Abc Imob & Fundo de Investimento Imobiliário Grand Plaza Shopping \\
\hline FII Europar & FII Europar \\
\hline FII Rb Cap I & RB Capital Renda I Fundo de Investimento Imobiliário - FII \\
\hline FII S F Lima & FII Continental Square Faria Lima \\
\hline FII Cshgshop & CSHG Brasil Shopping - Fundo de Investimento Imobiliário - FII \\
\hline FII HG Real & CSHG Real State - Fundo de Investimento Imobiliário - FII \\
\hline FII Hotel Mx & FII Hotel Maxinvest \\
\hline FII Bc Fund & Fundo de Investimento Imobiliário - FII BTG Pactual Corporate Office Fund \\
\hline FII Cshgjhsf & CSHG JHSF Prime Offices - Fundo de Investimento Imobiliário - FII \\
\hline FII Kinea & Kinea Renda Imobiliária - FII \\
\hline FII Max Ret & FII Max Retail \\
\hline FII Rbresid2 & RB Capital Desenvolvimento Residencial II - FII \\
\hline FII Rbprime1 & RB Capital Prime Realty I - FII \\
\hline FII Rb II & RB Capital Renda II - FII \\
\hline FII Trx Log & TRX Realty Logística Renda I - FII \\
\hline Fonte: CVM
\end{tabular}

Fonte: CVM

Para tanto, a fim de verificar quais variáveis influenciam o retorno dos FIIs no mercado brasileiro, foi estimado um modelo de regressão linear múltipla com base no Método dos Mínimos Quadrados Ordinários utilizando as seguintes variáveis:

- $\quad$ variável dependente: foram calculados os log-retornos trimestrais para cada um dos quinze fundos de investimentos imobiliários no período compreendido entre $1^{\circ}$ trimestre de 2011 e $1^{\circ}$ trimestre de 2015.

- variáveis explicativas: foram utilizadas os log-retornos trimestrais dos índices de mercado (IMA-B5, IMA-B5+, IRF-M, IBOVESPA, IDIV e IGMI-C).

A razão de este estudo adotar o período trimestral para as observações se dá pelo fato de a variável explicativa do segmento imobiliário, o IGMI-C, ter sua divulgação nessa mesma periodicidade.

Dentro deste contexto, o modelo pode ser especificado pela equação 2 apresentada a seguir.

$$
\begin{aligned}
\log (F I I)= & \beta_{o}+\beta_{1} \log (I M A-B 5)+\beta_{2} \log (I M A-B 5+)+\beta_{3} \log (I R F-M) \\
& +\beta_{4} \log (I B O V)+\beta_{5} \log (I D I V)+\beta_{6} \log (I G M I-C)+\varepsilon
\end{aligned}
$$

onde FII = retornos trimestrais das cotas dos fundos imobiliários; IMA-B5 = retornos dos títulos públicos indexados à inflação com maturidade inferior a 5 anos; IMA-B5+ = retornos dos títulos públicos indexados à inflação com maturidade superior a 5 anos; IRF-M = retornos do títulos públicos de juros prefixados; $\mathrm{IBOV}=$ é o retorno do IBOVESPA; IDIVI = retorno dos ativos bons pagadores de dividendos; IGMI-C = retorno do índice calculado para o mercado do setor imobiliário pela FGV.

Verifica-se através do teste de White e de Durbin-Watson a presença de heterocedasticidade e autocorrelação dos resíduos no modelo acima. Caso essas anomalias sejam detectadas, será utilizado o OLS robusto através do ajuste robusto de Newey-West. 


\section{ANÁLISE DOS RESULTADOS}

A relação entre o risco e o retorno médio trimestral das séries dos FIIs, IMA-B5, IMA-B5+, IRF-M, IBOV, IDIV e IGMI-C foi construída para realizar uma análise comparativa por meio do Figura 1.

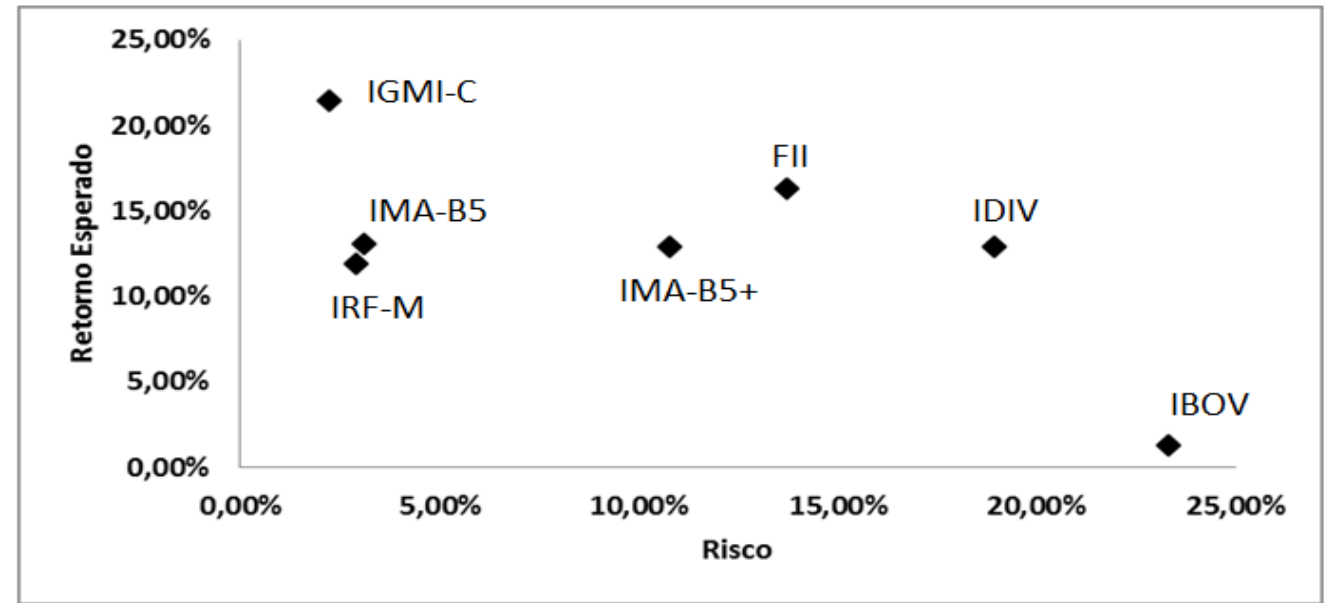

Figura 1. Relação entre o Risco e o Retorno das Variáveis Analisadas (20011 a 2015) Fonte: Elaborado pelos autores. Dados trimestrais no período de 2011 a 2015.

Observa-se que a série dos FIIs apresenta um comportamento similar ao IMA-B5+ e ao índice IDIV, evidenciando o comportamento híbrido dos fundos imobiliários já discutido anteriormente. Os fundos imobiliários possuem tanto o risco como o retorno médio superiores aos indicadores do mercado de renda fixa. Há também uma melhor relação entre o risco e o retorno médio dos FIIs em comparação aos indicadores do mercado de renda variável (IBOV e IDIV). No entanto, o IGMI-C superou os FIIs na relação entre o risco e o retorno médio. A Figura 2 mostra o retorno acumulado da série do FII em comparação às variáveis explicativas selecionadas neste estudo para o mercado de renda fixa (IMA-B5, IMA-B5+, IRF-M).

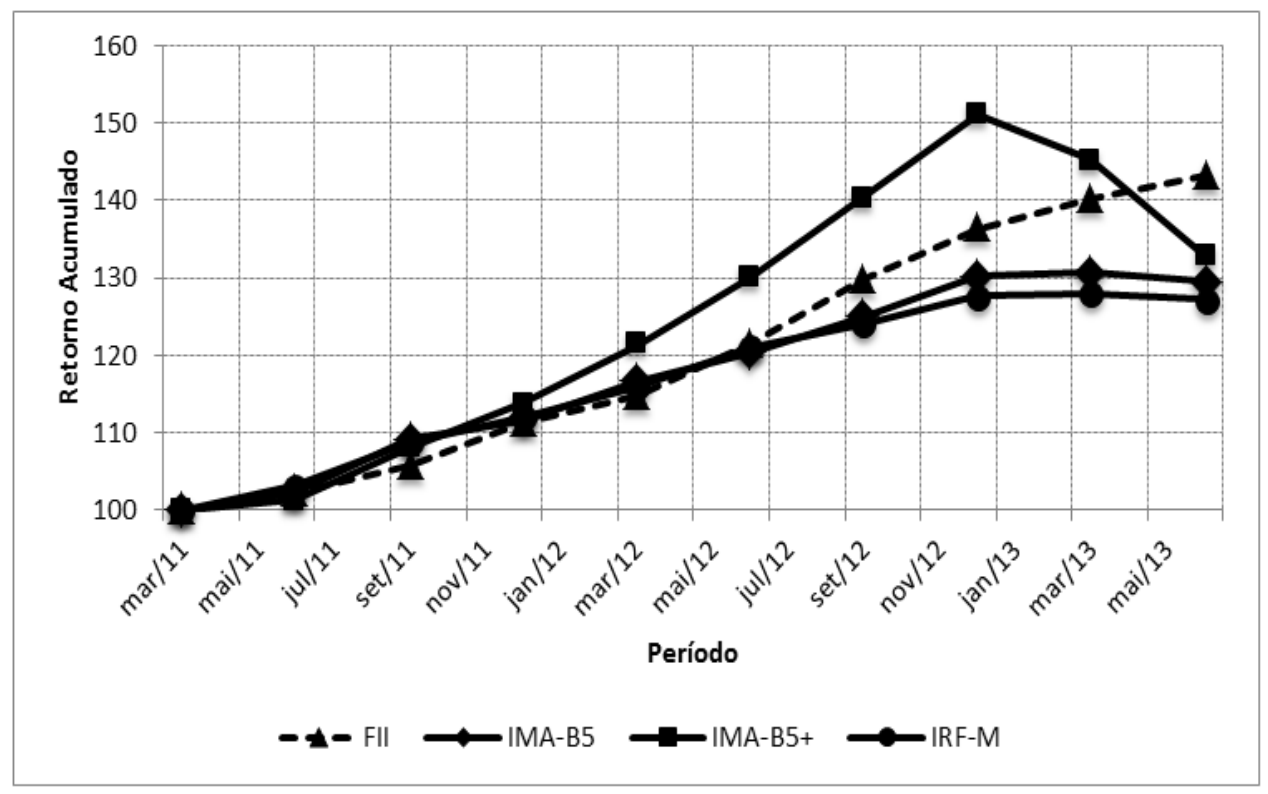

Figura 2. Retorno Acumulado dos indicadores IMA-B5, IMA-B5+, IRF-M e da Carteira dos Fundos Imobiliários (2011 a 2013).

Fonte: Elaborado pelos autores. Dados coletados na base do Economática e FGV no período de 01/2011 a 03/2015.

Verifica-se que o FII apresentou um retorno acumulado superior aos indicadores de renda fixa durante o período de 2011-2015 em 52\% dos casos analisados. Já o Gráfico 3 mostra a evolução do retorno acumulado dos FIIs em comparação aos indicadores do mercado de renda variável (IBOV e IDIV) e do IGMI-C. 


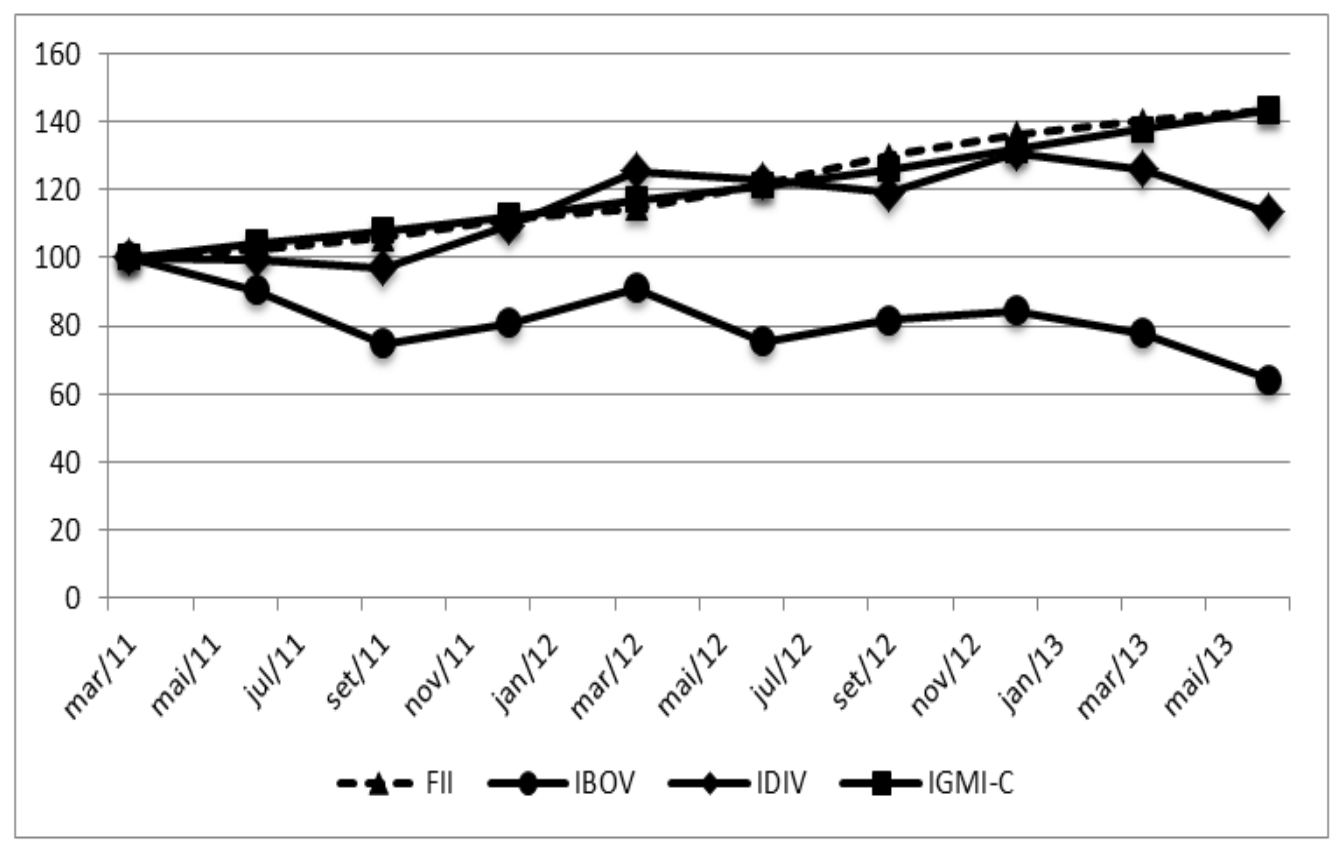

Figura 3. Retorno Acumulado dos indicadores IBOV, IDIV, IGMI-C e da Carteira dos Fundos Imobiliários (2011 a 2015).

Fonte: Elaborado pelos autores. Dados coletados na base do Economática e FGV no período de 01/2011 a 03/2015.

Nota-se que os fundos imobiliários apresentaram um retorno acumulado superior ao dos indicadores do mercado de renda variável. No entanto, o retorno acumulado do IGMI-C é similar ao obtido pelos FIIs no período analisado. As estatísticas descritivas obtidas para os indicadores analisados foram:

Tabela 1. Estatísticas Descritivas para as Variáveis Analisadas - 2011 a 2015

\begin{tabular}{ccccc}
\hline Variáveis & Média & Desvio-Padrão & Mínimo & Máximo \\
\hline FIIs & 0.0356 & 0.0821 & -0.3123 & 0.4072 \\
IMA-B5 & 0.0239 & 0.0129 & -0.0030 & 0.0677 \\
IMA-B5+ & 0.0250 & 0.0539 & -0.0835 & 0.0793 \\
IRF-M & 0.0259 & 0.0174 & -0.0062 & 0.0539 \\
IBOV & -0.0234 & 0.1154 & -0.1792 & 0.1271 \\
IDIV & 0.0259 & 0.0747 & -0.1011 & 0.1469 \\
IGMI-C & 0.0422 & 0.0036 & 0.0362 & 0.0483 \\
\hline
\end{tabular}

Fonte: Elaborado pelos Autores. Estatísticas descritivas calculadas no período total de 2011 a 2015

Os fundos imobiliários e o IGMI-C apresentaram um retorno médio de 3,56\% e 4,22\% respectivamente. Esses foram os maiores retornos médios em comparação as demais variáveis estudadas. No entanto, o mercado acionário possui um retorno médio negativo (-2,34\%) acompanhado de uma maior volatilidade em relação ao mercado imobiliário e de renda fixa. Os resultados do modelo de regressão realizados no software STATA podem ser resumidos na Tabela a seguir. 
Tabela 2. Resultados Obtidos para o Modelo de Regressão no período de 2011 a 2015

\begin{tabular}{ccccccc}
\hline Variáveis & Coeficiente & Erro-Padrão & $\mathbf{t}$ & \multicolumn{1}{c}{ Valor-P } & \multicolumn{2}{c}{ Intervalo de confiança 95\% } \\
\hline IMA-B5 & $-2.6483 * * *$ & 1.1493 & -2.63 & 0.0100 & -4.6130 & -0.5639 \\
IRF & $64839 * * *$ & 1.7392 & 3.92 & 0.0000 & 3.4302 & 10.3210 \\
IBOV & $04939 * * *$ & 0.1629 & 4.66 & 0.0000 & 0.3830 & 0.9901 \\
IDIV & $-0.5302 * * *$ & 0.2455 & -3.62 & 0.0000 & -1.3302 & -0.3823 \\
IGMI-C & $6.8392 * * *$ & 3.2159 & 2.22 & 0.0350 & 0.4259 & 13.1215 \\
constante & $-0.3294 * * *$ & 0.1938 & -2.25 & 0.0340 & -0.6020 & -0.0456 \\
\hline
\end{tabular}

Fonte: Elaborado pelos Autores. Níveis de Significância: ***1\%; **5\% e *10\%. A regressão acima considerou os log-retornos trimestrais dos FIIs como variável dependente e os log-retornos trimestrais dos indicadores do mercado de renda fixa (IMA -B5; IMA-B5+ e IRF-M), dos indicadores do mercado de renda variável (IBOV e IDIV) e do mercado imobiliário (IGMI-C) como variáveis explicativas no período compreendido entre 2011 a 2015. A variável IMA-B5+ foi retirada da análise, pois seu Valor-P foi superior a 5\%. O R ao quadrado ajustado do modelo de regressão acima foi de $22.67 \%$. O teste de White indicou um valor-P de 0.5427 , indicando que os erros do modelo de regressão podem ser considerados homocedásticos. Já o teste de Durbin-Watson aponta para um Valor-P de 0.1112 , mostrando que os erros não podem ser considerados autocorrelacionados serialmente. Assim, o Método dos Mínimos Quadrados Ordinários (OLS clássico) pode ser utilizado a fim de estimar parâmetros não-viesados e consistentes.

A variável dependente, que é o log-retorno do FII, pode ser explicada por todas as variáveis utilizadas com 95\% de confiança. Os coeficientes mostram que os fundos foram positivamente correlacionados com o IRF-M, IBOVESPA e o IGMI-C ao nível de significância de 5\%. Este resultado corrobora as expectativas iniciais de um desempenho bastante atrelado às variações da bolsa e do mercado imobiliário.

Com relação ao IMA-B5, uma diminuição dos retornos dos títulos públicos NTN-B pode dar maior atratividade financeira aos fundos imobiliários pelo substancial aumento do valor de mercado dos imóveis comerciais no Brasil no período analisado. Vale ressaltar que os fundos imobiliários também oferecem uma proteção contra a inflação devido ao reajuste dos aluguéis. Os imóveis comerciais utilizados como lastro dos Fundos Imobiliários podem apresentar uma defasagem temporal em relação ao retorno do fundo..

Quanto ao índice de Dividendos - IDIV, possivelmente, o resultado do sinal do coeficiente diferente do esperado apresentado pode ser atribuído pela própria delimitação do período da amostra e seu respectivo comportamento frente aos retornos dos FIIs selecionados neste estudo. Acrescenta-se ainda que a análise deste trabalho compreende um período temporal relativamente curto devido à restrição imposta para a utilização da variável IGMI-C.

O IRF-M apresentou resultado em linha com o esperado, refletindo o comportamento das taxas de juros de mercado em antecipação aos movimentos esperados da Selic esperados pelo mercado, funcionando como uma proxy do custo de oportunidade para a decisão do investimento em FII.

Em virtude dos fundos imobiliários serem negociados em bolsa era esperado uma influência da volatilidade do índice Ibovespa sobre as cotas dos fundos. Este resultado é corroborado pelos estudos anteriores já mencionados. Por fim, em relação ao IGMI-C, os FIIs apresentam uma correlação positiva com a valorização do mercado imobiliário e com os rendimentos dos aluguéis.

Nota-se pelos módulos dos coeficientes do modelo de regressão que os FIIs apresentam maior relação com a taxa de juros prefixada e com o retorno do mercado imobiliário, corroborando com os resultados empíricos de Niskanen e Falkenbach (2010) e Ghosh, Miles e Sirmans (1996). 


\section{CONCLUSÃO}

Os Fundos Imobiliários são veículos de investimentos que reúnem investidores cujo objetivo é aplicar seus recursos em ativos de cunho imobiliário. As ofertas públicas dos fundos de investimento imobiliário vêm crescendo ano a ano, e a negociação de suas cotas, embora ainda baixa, também vem apresentado crescimento constante, tornando o investimento em fundos imobiliários uma opção bastante acessível e satisfatória para os investidores de qualquer porte.

Este trabalho teve como objetivo avaliar o estilo de uma amostra de fundos de investimentos imobiliários utilizando uma variante do modelo tradicional de Sharpe e as seguintes variáveis: IMA-B5, IMA-B5+, IBOVESPA, IDIV, IRF-M e IGMI-C.

Os índices de renda fixa IRF-M e IMA-B5 apresentaram resultados em linha com o esperado, mostraram que os retornos dos FIIs são influenciados pelo comportamento das taxas de juros do mercado e pela inflação. Quanto aos índices de renda variável, o Ibovespa apresentou comportamento conforme esperado e de acordo com a literatura. Já o IDIV, o resultado do sinal do coeficiente diferente do esperado pode ser atribuído pela própria delimitação do período da amostra. Desta forma, tais resultados contribuem para averiguar a característica híbrida dos FIIs já declarada na literatura acadêmica. A correlação dos FIIs com o IBOV evidencia que os investidores podem obter benefícios de diversificação.

Quanto ao IGMI-C, o resultado ficou dentro das expectativas iniciais, mostrando que a variável explicativa que representa o retorno do mercado imobiliário de imóveis comerciais influencia significativamente os retornos dos FIIs . Mesmo que o fundo imobiliário esteja naturalmente lastreado a um ativo real, considerado com um ativo seguro e com baixa volatilidade, verificou-se que, pela dinâmica inerente às variações de preços e riscos associados aos FIIs, há um caráter híbrido desses fundos no que tange ao mercado de renda fixa e variável.

É importante salientar que o período de análise abrangeu a recuperação da crise financeira do Sub-prime de 2008, o que pode exercer uma influência nos resultados encontrados. Como sugestão para futuros trabalhos, seria interessante testar os resultados de uma amostra mais ampla, de forma que os fatores exógenos da recente crise não exerçam influência significativa.

Há de se considerar também que o mercado imobiliário é cíclico e, no período abrangido por esse estudo, há uma significativa expansão deste setor, em parte pela grande oferta de crédito para tal mercado. Por fim, não obstante seriam necessários outros estudos em busca de maiores evidências para verificar como estes fundos reajam no curto e longo prazo frente as variáveis do mercado de renda fixa e variável.

\section{REFERÊNCIAS}

ALEXANDER, Carol; DIMITRIU, Anca. The Art of Investing in Hedge Funds: Fund Selection and Optimal Allocations. In: EFMA 2004 Basel Meetings Paper. 2004.

ALMEIDA, A. R.; MENDES, B. V.; NAZARETH, M. Análise de Estilo Robusta. In: Encontro Brasileiro de Finanças, 7, 2007. São Paulo. Anais...São Paulo, 2007.

BRASIL. Comissão de Valores Mobiliários (CVM). Instrução Normativa n 472, de 31 de outubro de 2008. Dispõe sobre a constituição, a administração, o funcionamento, a oferta pública de distribuição de cotas e a divulgação de informações dos Fundos de Investimento Imobiliário - FII. Revoga as Instruções CVM n ${ }^{\circ} 205$, de 14 de janeiro de 1994, no 389, de 3 de junho de 2003, no 418, de 19 de abril de 2005 e $n^{\circ} 455$, de 13 de junho de 2007. Acrescenta o Anexo III-B à Instrução CVM no 400, de 29 de dezembro de 2003. Disponível em: <http://www.cvm.gov.com.br>. Acesso em: 31/08/2013.

.Caderno $\mathrm{n}^{\circ} 6$ - Fundos de Investimento Imobiliário, 2010. Disponível em: <http://www.cvm.gov. 
br/port/protinv/caderno6.asp>. Acesso em 31/07/2014.

BROWN, Stephen J.; GOETZMANN, William N. Mutual fund styles. Journal of financial Economics, v. 43, n. 3, p. 373-399, 1997.

CHAN, Louis KC; CHEN, Hsiu-Lang; LAKONISHOK, Josef. On mutual fund investment styles. Review of financial studies, v. 15, n. 5, p. 1407-1437, 2002.

CLAYTON, Jim; MACKINNON, Greg. The time-varying nature of the link between REIT, real estate and financial asset returns. Journal of Real Estate Portfolio Management, v. 7, n. 1, p. 43-54, 2001.

COELHO, Gustavo Teixeira; MINARDI, Andrea Maria AF; LAURINI, Márcio Poletti. Uma investigação sobre os Estilos Gerenciais e Riscos de Mercado de Fundos Multimercados Brasileiros. Insper Working Paper, Insper Instituto de Ensino e Pesquisa, 2009.

COSENTINO, R. M. A.; ALENCAR, C. T. Fundos de Investimento Imobiliário: Análise do Desempenho e Comparação com US-REITs, UK-REITs, G-REITs e SIIC. In: 11a Conferência Internacional da LARESLatin American Real Estate Society. 2011.

EID, Gabriel Samento. Análise da Introdução de fundos imobiliários em uma carteira de investimentos. Monografia (requisito para aprovação na disciplina de Monografia II) - Faculdade de Campinas. Campinas, 2010.

FERREIRA, Fernanda Maria. Fundos de Investimento Imobiliário - Governança Corporativa. Dissertação (Mestrado em Engenharia) - Escola politécnica - Universidade de São Paulo. São Paulo, 2011.

FRANKE, Gabriel de Azevedo. Fundo de Investimento imobiliário como alternativa de investimento no mercado financeiro - Um estudo comparativo. Monografia (Trabalho de conclusão - Bacharel em Administração) Departamento de Ciências Administrativas da Universidade Federal do Rio Grande do Sul, Porto Alegre, 2012.

FUNG, William; HSIEH, David A. Empirical characteristics of dynamic trading strategies: The case of hedge funds. Review of financial studies, v. 10, n. 2, p. 275-302, 1997.

GHOSH, Chinmoy; MILES, Mike; SIRMANS, C. F. Are REITS stocks?. Real Estate Finance, v. 13, p. 46-53, 1996.

GLASCOCK, John L.; LU, Chiuling; SO, Raymond W. REIT returns and inflation: perverse or reverse causality effects?. The Journal of Real Estate Finance and Economics, v. 24, n. 3, p. 301-317, 2002.

HE, Ling T.; WEBB, James. R.; MYER, F.C. Neil. Interest Rate Sensitivities of REIT Returns. International Real Estate Review, v. 6, n.1, p. 1-21, 2003.

HUANG, C.; LEE, Y. The Relationship between Oil Price Growth and REIT Returns. International Research Journal of Finance and Economics, v. 33, p. 120-133, 2009.

JENSEN, Michael C. The performance of mutual funds in the period 1945-1964. The Journal of finance, v. 23, n. 2, p. 389-416, 1968.

KUCKO, Irena. Investment Fund Portfolio Selection Strategy. Business: Theory and Practice, v. VIII, n. 4, p. $214-$ 220, 2007.

MUGNAINI, Alexandre; SILVA, Wesley Vieira da; SOUZA, Alceu; DEL CORSO, Jansen Maia. Análise da Eficiência de Mercado e Performance de Fundos de Investimentos Imobiliários Negociados na Bovespa. Revista Capital Científico do Setor de Ciências Sociais Aplicadas, v.6, n.1, p. 65-86, 2008.

NISHIGAKI, Hideki. An analysis of the relationship between US REIT returns. Economics Bulletin, v. 13, n. 1, p. 1-7, 2007. 
NISKANEN, Jaakko; FALKENBACH, Heidi. REITs and correlations with other asset classes: a European perspective. Journal of Real Estate Portfolio Management, v. 16, n. 3, p. 227-239, 2010.

PORTO, Paola Torneri; LIMA JUNIOR, João da Rocha. Portfólios de investimentos em edifícios de escritório para locação: análise de desempenho. In: X Conferência Internacional da LARES. São Paulo, 2010.

SHARPE, William F. Determining a fund's effective asset mix. Investment Management Review, v. 2, n. 6, p. 5969, 1988.

. Asset allocation: Management style and performance measurement. The Journal of Portfolio Management, v. 18, n. 2, p. 7-19, 1992.

SCHUTT, Isabel Gaio; CALDEIRA, João Frois. Análise de Estilo Dinâmica de Fundos Multimercados: Aplicação para o Mercado Brasileiro. In: Encontro Nacional de Economia, XLI, 2014. São Paulo. Anais...São Paulo, 2013.

UQBAR. Educação e Informação Financeira Avançada. Guia do Investidor Fundo de Investimento Imobiliário, 2013.

VALIM, Vinícius Ziegler. Riscos e Cuidados com Investimentos no Mercado Imobiliário. Revista Especialize Online IPOG, v.6, n.06, p. 1-15, 2013.

VILELLA, Paulo Alvarez; LEAL, Ricardo Pereira Câmara. O Desempenho de Fundos de Renda Fixa e o Índice de Renda Fixa de Mercado (IRFM). RAE - eletrônica - v. 7, n. 1, jan./jun. 2008.

YOSHINAGA, Cláudia Emiko; ODA, André Luiz; LUCCHESI, Eduardo Pozzi; CASTRO JUNIOR, Francisco Henrique Figueiredo de. Análise das diferenças entre os Fundos Multimercados com e sem Alavancagem através da aplicação da Análise de Estilo e da Análise de Conglomerados. In: SEMEAD, X, 2007. São Paulo. Anais...São Paulo, 2007. 